\title{
Validation of gas temperature measurements by OES in an atmospheric air glow discharge with water electrode using Rayleigh scattering
}

\author{
Citation for published version (APA): \\ Verreycken, T., Gessel, van, A. F. H., Pageau, A., \& Bruggeman, P. J. (2011). Validation of gas temperature \\ measurements by OES in an atmospheric air glow discharge with water electrode using Rayleigh scattering.
} Plasma Sources Science and Technology, 20(2), 024002-1/6. https://doi.org/10.1088/0963-0252/20/2/024002

DOI:

10.1088/0963-0252/20/2/024002

Document status and date:

Published: 01/01/2011

\section{Document Version:}

Publisher's PDF, also known as Version of Record (includes final page, issue and volume numbers)

\section{Please check the document version of this publication:}

- A submitted manuscript is the version of the article upon submission and before peer-review. There can be important differences between the submitted version and the official published version of record. People interested in the research are advised to contact the author for the final version of the publication, or visit the DOI to the publisher's website.

- The final author version and the galley proof are versions of the publication after peer review.

- The final published version features the final layout of the paper including the volume, issue and page numbers.

Link to publication

\footnotetext{
General rights

- You may freely distribute the URL identifying the publication in the public portal. follow below link for the End User Agreement:

www.tue.nl/taverne

\section{Take down policy}

If you believe that this document breaches copyright please contact us at:

openaccess@tue.nl

providing details and we will investigate your claim.
}

Copyright and moral rights for the publications made accessible in the public portal are retained by the authors and/or other copyright owners and it is a condition of accessing publications that users recognise and abide by the legal requirements associated with these rights.

- Users may download and print one copy of any publication from the public portal for the purpose of private study or research.

- You may not further distribute the material or use it for any profit-making activity or commercial gain

If the publication is distributed under the terms of Article $25 \mathrm{fa}$ of the Dutch Copyright Act, indicated by the "Taverne" license above, please 
Validation of gas temperature measurements by OES in an atmospheric air glow discharge with water electrode using Rayleigh scattering

This article has been downloaded from IOPscience. Please scroll down to see the full text article.

2011 Plasma Sources Sci. Technol. 20024002

(http://iopscience.iop.org/0963-0252/20/2/024002)

View the table of contents for this issue, or go to the journal homepage for more

Download details:

IP Address: 131.155.110.104

The article was downloaded on 06/04/2011 at 10:06

Please note that terms and conditions apply. 


\title{
Validation of gas temperature measurements by OES in an atmospheric air glow discharge with water electrode using Rayleigh scattering
}

\author{
T Verreycken ${ }^{1,2}$, A F H van Gessel ${ }^{1}$, A Pageau ${ }^{1,3}$ and P Bruggeman ${ }^{1}$ \\ ${ }^{1}$ Eindhoven University of Technology, Department of Applied Physics, PO Box 513, 5600 MB \\ Eindhoven, The Netherlands \\ ${ }^{2}$ Ghent University, Department of Applied Physics, Jozef Plateaustraat 22, B-9000 Gent, Belgium \\ ${ }^{3}$ Ecole Polytechnique de l'Université d'Orléans, Laboratoire d'Electronique et d'Optique, 8 rue Léonard \\ de Vinci, 45072 Orléans cedex 2, France \\ E-mail: p.j.bruggeman@tue.nl
}

Received 30 June 2010, in final form 2 November 2010

Published 1 April 2011

Online at stacks.iop.org/PSST/20/024002

\begin{abstract}
Rayleigh scattering is used to determine the gas temperature of an atmospheric pressure dc excited glow discharge in air with a water electrode. The obtained temperatures are compared with calculated rotational temperatures measured by optical emission spectroscopy of $\mathrm{OH}(A-X)$ and $\mathrm{N}_{2}(C-B)$. At a current of $15 \mathrm{~mA}$ a deviation is found between $T_{\mathrm{rot}}(\mathrm{OH})$ and the gas temperature obtained from Rayleigh scattering of about $1000 \mathrm{~K}$. The gas temperatures obtained from Rayleigh scattering, $\mathrm{N}_{2}(C)$ and $\mathrm{OH}(A)$ in the positive column are, respectively, $2600 \pm 100 \mathrm{~K}, 2700 \pm 150 \mathrm{~K}$ and $3600 \pm 200 \mathrm{~K}$. It is shown that the rotational temperature of $\mathrm{N}_{2}(C)$ is a reliable measurement of the gas temperature while this is not the case for $\mathrm{OH}(A)$. The results are explained in the context of quenching processes of the excited states. Spatially resolved gas temperatures in both longitudinal and radial directions are presented. The observed strong temperature gradients near the electrodes are checked to be consistent with the power dissipation and the heat transfer in the discharge. The effect of the polarity of the water electrode and filamentation on the measured temperatures is discussed.
\end{abstract}

(Some figures in this article are in colour only in the electronic version)

\section{Introduction}

In view of the search for non-thermal atmospheric pressure plasmas with respect to biomedical and environmental applications, discharges in and in contact with liquids have gained increasing interest in the last decade [1]. Existing applications of plasmas in liquid include surgery [2], lithotripsy [3] and (miniaturized) chemical analysis [4]. Water containing plasmas produce strongly oxidizing species $\left(\mathrm{OH}, \mathrm{O}, \mathrm{H}_{2} \mathrm{O}_{2}\right.$, etc) and UV radiation. However, due to the complex chemistry and the fact that the discharges are often inaccessible for advanced laser diagnostics, several important questions remain unanswered, especially in view of radical densities. In order to understand the radical production, among which $\mathrm{OH}$ is one of the most important radicals for applications, it is necessary to have accurate diagnostics to measure the plasma parameters such as the electron temperature $T_{\mathrm{e}}$, the electron density $n_{\mathrm{e}}$ and the gas temperature $T_{\mathrm{g}}$, which determine the chemistry together with the gas composition. This paper tackles the issues with the gas temperature determination already introduced in former work of the authors (see further). The gas temperature is an important parameter as most chemical reactions are strongly temperature dependent, e.g. thermal dissociation reactions of water.

The atmospheric pressure glow discharge with a water electrode has been studied under similar discharge conditions by several researchers [5-9]. Nonetheless there is a large difference in the gas temperatures measured. Although in 


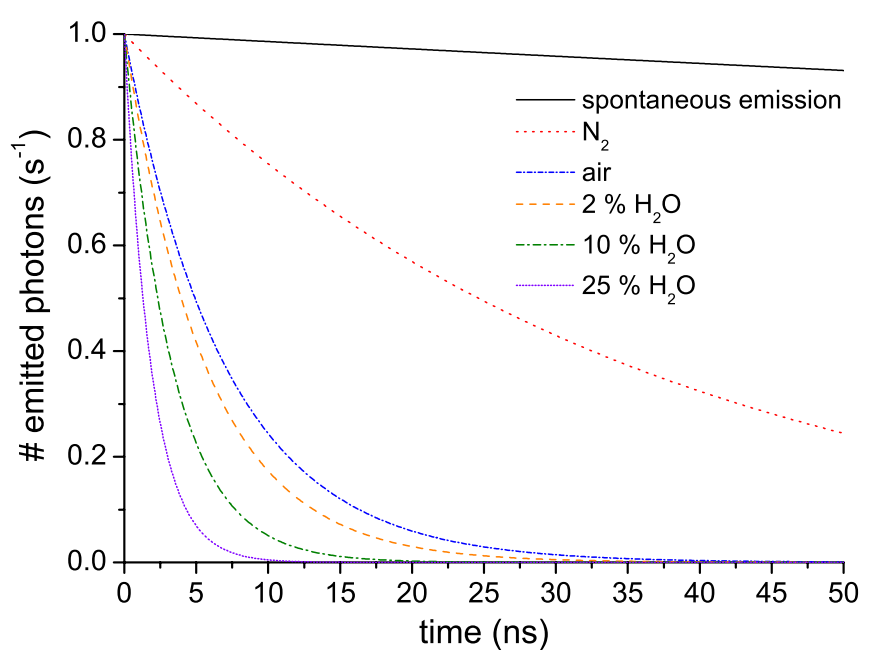

Figure 1. The number of photons emitted per unit time by $\mathrm{OH}(A)$ for a given initial concentration of $\mathrm{OH}(A)$ in the case of spontaneous emission, $\mathrm{N}_{2}$ and air as background gas and the background gas containing $2 \%, 10 \%$ and $25 \%$ of water vapour.

atmospheric pressure $\mathrm{He}, \mathrm{N}_{2}$ and air discharges with water vapour impurities the rotational temperature of $\mathrm{OH}(A)$ is a good indicator of the gas temperature [10-12], for discharges in and in contact with liquids significantly larger rotational temperatures are often obtained from $\mathrm{OH}(A-X)$ emission than from other molecules such as $\mathrm{N}_{2}$ [13-15]. In previous work of Bruggeman et al [14] it is shown that for a significant amount of water vapour in the discharge $\left(>900 \mathrm{ppm} \mathrm{H}_{2} \mathrm{O}\right.$ in $\left.\mathrm{He}\right)$ the rotational population distribution of $\mathrm{OH}(A-X)$ becomes nonBoltzmann. Although this non-equilibrium is unexpected in highly collisional atmospheric pressure plasmas, it does occur due to the significant reduction in the lifetime of $\mathrm{OH}(A)$ by strong collisional quenching of $\mathrm{OH}(A)$.

The rotational energy transfer (RET) rate is estimated to be of the order of $10^{-15} \mathrm{~m}^{3} \mathrm{~s}^{-1}[16,17]$. As the neutral density is of the order of $3 \times 10^{24} \mathrm{~m}^{-3}\left(T_{\mathrm{g}} \approx 2500 \mathrm{~K}\right)$ this leads to about three RETs each nanosecond or somewhat less. Taking into account that several collisions inducing RET are necessary and that the RET rate goes down with increasing rotational number, it takes a few nanoseconds up to about $10 \mathrm{~ns}$ to go from non-equilibrium to a Boltzmann distribution. Figure 1 illustrates the number of emitted photons per unit time for a given initial concentration of $\mathrm{OH}(A)$ at $t=0$; as a reference the spontaneous emission is provided as well (the radiative lifetime of $\mathrm{OH}(A)$ is about $700 \mathrm{~ns}$ ). At high pressure a large part of the $\mathrm{OH}(A)$ molecules is depopulated by collisional quenching. The quenching of $\mathrm{OH}(A)$ by $\mathrm{O}_{2}$ and especially $\mathrm{H}_{2} \mathrm{O}$ has a larger cross section than that of $\mathrm{OH}(A)$ by $\mathrm{N}_{2}$. When the water concentration increases to $10 \%$ or more the effective radiative lifetime reduces so much that almost all emission occurs during the first few nanoseconds and thermalization is no longer possible. These concentrations are realistic for plasmas in contact with liquids [9, 18, 19].

Because of quenching the rotational population distribution of $\mathrm{OH}(A-X)$ does not represent a kinetic temperature (the gas temperature), but that a rotational population distribution like $\mathrm{OH}(A)$ is produced, which is non-Boltzmann, as investigated at very low pressures [20,21]. As the quenching rates for $\mathrm{N}_{2}(C)$ and $\mathrm{OH}(A)$ by $\mathrm{H}_{2} \mathrm{O}$ are of the same order of magnitude [22], one would think that the same reasoning is valid for $\mathrm{N}_{2}(C)$. However, the energy difference between the rotational states of $\mathrm{N}_{2}$ is smaller than in the case of $\mathrm{OH}$, since the rotational constant is inversely proportional to the mass of the molecule. As a consequence, thermalization is expected to be obtained more easily in the case of $\mathrm{N}_{2}$. However, up to now it has not yet been confirmed if the rotational temperature is a good representation of the gas temperature.

In this paper gas temperatures obtained from the rotational bands of $\mathrm{OH}(A-X)$ and $\mathrm{N}_{2}(C-B)$ are discussed and compared with gas temperatures measured in this work by Rayleigh and Raman scattering. Opposed to rotational temperatures of excited species, which depend upon the excitation kinetics and thus directly on the plasma parameters, Rayleigh scattering measurements offer an alternative way to determine the gas temperature, by measuring the gas density without any potential dependence on the excitation or production mechanism of excited species. First the experimental setup and methods are presented. In section 3 the gas temperatures in the positive column, obtained by Rayleigh scattering, are compared with the rotational temperatures obtained from optical emission spectroscopy (OES) of $\mathrm{OH}$ and $\mathrm{N}_{2}$ and Raman scattering. Section 4 deals with the spatial temperature distribution in the glow discharge. The consistency of the measured temperature gradients with the power dissipation and expected heat transfer in the discharge is also verified. Finally, the effect of the polarity of the liquid electrode on the gas temperature is discussed in section 5 .

\section{Experimental setup and methods}

The electrode configuration is a metal anode-liquid cathode system in open air and has been reported in detail in previous work $[9,23]$. Tap water with a conductivity of $250 \mu \mathrm{S} \mathrm{cm}^{-1}$ is used as liquid electrode. The distance between the water electrode and the cone shaped stainless steel electrode is fixed at $3 \mathrm{~mm}$. The discharge is excited by a Spellman dc power supply $(6 \mathrm{kV}, 100 \mathrm{~mA})$; a ballast resistor of $25 \mathrm{k} \Omega$ is placed in series. Gas temperatures were measured in the current range $15-50 \mathrm{~mA}$. In this current range the voltage is constant and equal to $1.09 \pm 0.02 \mathrm{kV}$.

The light originating from the middle of the positive column of the glow discharge is collimated by a lens to an optical fibre. The spatial resolution of the OES is approximately $1 \mathrm{~mm}$. High resolution spectra of the $\mathrm{OH}$ band $\left(A^{2} \Sigma^{+} \rightarrow X^{2} \Pi(0-0), 309 \mathrm{~nm}\right)$ are obtained with a double echelle monochrometer (DEMON) (resolution $\approx 5 \mathrm{pm}$ FWHM). A grating monochromator (ACTON) of lower resolution $(\approx 1 \AA \mathrm{FWHM})$ is used to measure the nitrogen $\operatorname{spectra}\left(C^{3} \Pi_{\mathrm{u}} \rightarrow B^{3} \Pi_{\mathrm{g}}(0-0), 337 \mathrm{~nm}\right)$.

The rotational temperature of $\mathrm{N}_{2}(C)$ is determined from the emission spectrum of $\mathrm{N}_{2}(C-B)(0,0)$ at $337 \mathrm{~nm}$ with Specair [24], a program to simulate spectra. In this program it is assumed that the rotational states are in equilibrium and characterized by a Boltzmann distribution with an intensity 


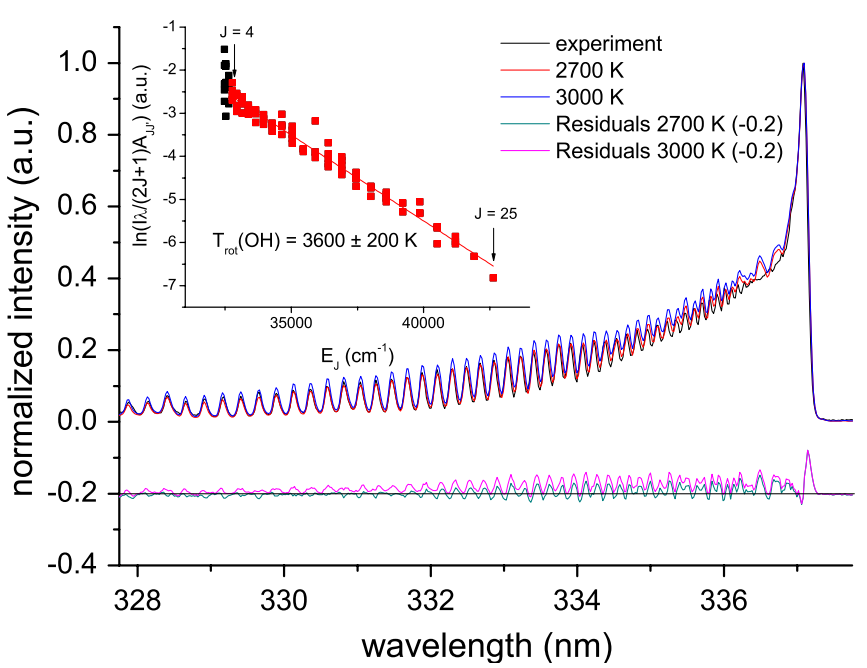

Figure 2. Experimental and modelled spectra $\left(T_{\mathrm{rot}}=2700 \mathrm{~K}\right.$ and $\left.T_{\text {rot }}=3000 \mathrm{~K}\right)$ of $\mathrm{N}_{2}(C-B)$ in the positive column at $15 \mathrm{~mA}$. The inset graph shows the Boltzmann plot of $\mathrm{OH}(A-X)$ measured in the positive column at $15 \mathrm{~mA}$. $T_{\text {rot }}(\mathrm{OH})$ is calculated from $J=4$ up to $J=25$.

given by

$$
I_{J J^{\prime}}=a(2 J+1) A_{J J^{\prime}} \nu_{J J^{\prime}} \exp \left(-\frac{E_{J}}{k T_{\text {rot }}}\right)
$$

where $a$ is a constant, $A_{J J^{\prime}}$ is the rotational transition probability, $v_{J J^{\prime}}$ is the frequency of the transition from rotational level $J$ to $J^{\prime}$ and $E_{J}$ is the rotational energy. The rotational temperature of $\mathrm{OH}(A)$ is derived from the emission of the $\mathrm{OH}(A-X)(0-0)$ transition at $309 \mathrm{~nm}$ with the Boltzmann plot method. An example of a Specair simulation and a Boltzmann plot of $\mathrm{OH}(A)$ for rotational numbers $J=4-25$ is shown in figure 2. For the determination of the rotational temperature of $\mathrm{OH}(A)$ a two-temperature fit (as done in [9]) is not possible as only the first 3 rotational numbers deviate from the second temperature. The reason for this is that quenching depends strongly on the gas composition. The presence of oxygen basically increases the quenching rates significantly compared with e.g. $\mathrm{N}_{2}$ (and also He [9]), as can be seen in figure 1. The deviation from thermal equilibrium begins to appear thus at smaller rotational numbers $(J=4$ instead of $J=13$ in [9]). In this case it is also doubtful if the three states for $J<4$ are in equilibrium because this will be a gradual transition and not an exact transition for a certain rotational state. The error on the rotational temperature of $\mathrm{OH}(A)$ is obtained by fitting the slope of the Boltzmann plot. In figure 2 the residuals of the fitted spectra of $\mathrm{N}_{2}$ are shown as well. The errors on the $\mathrm{N}_{2}(C-B)$ rotational temperature are based on the fact that the error on the fit is significantly larger (approximately 10\%) by increasing/decreasing the best fit temperature with the error value of the temperature.

Rayleigh scattering is the elastic scattering of photons by heavy particles (atoms, ions and molecules). The inelastic scattering of photons by molecules, which can undergo a rotational or vibrational transition, is called Raman scattering. As is seen by an example of a rotational Raman spectrum in figure 3 , the rotational structure is partly resolved and is mainly

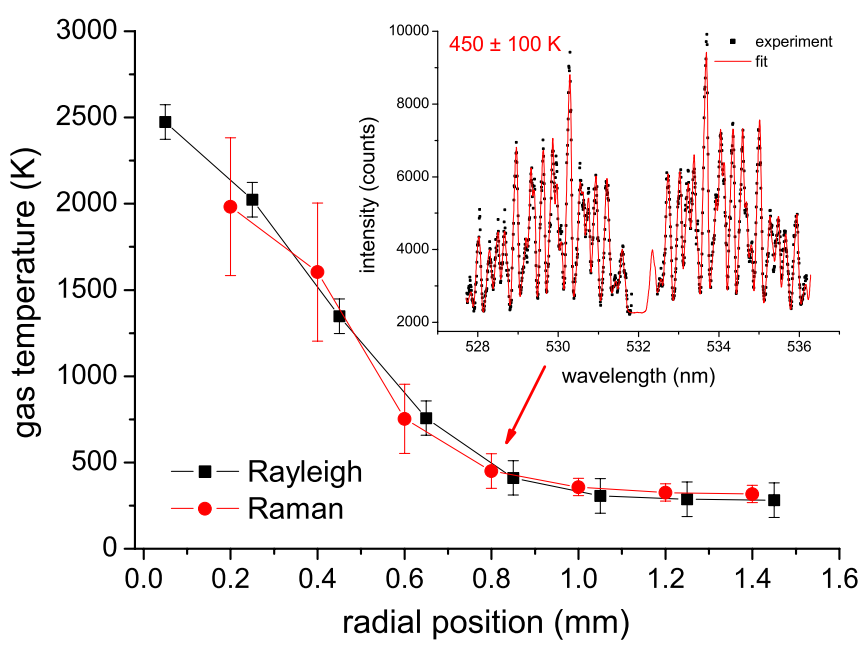

Figure 3. Radial profiles of the gas temperature in the positive column at $15 \mathrm{~mA}$ obtained by Rayleigh and Raman scattering. The inset graph shows a Raman spectrum at radial position $0.8 \mathrm{~mm}$.

a superposition of $\mathrm{O}_{2}$ and $\mathrm{N}_{2}$ contributions. The relative intensity of the scattered light by the different rotational excited states can thus be fitted to get a temperature characteristic of the ground state $\mathrm{O}_{2}$ and $\mathrm{N}_{2}$ rotational distributions. The problem of distortion of the rotational temperature by the formation process of the molecule, which can occur for electronically excited species with a short life time, does not occur for ground state molecules of the background gas.

The fit of the Raman spectra is done by theoretically calculating the wavelengths of the different Raman peaks (Stokes and anti-Stokes) for a laser wavelength of $532 \mathrm{~nm}$, according to [25]. The relative intensity of the peaks is obtained by calculating the differential cross sections and the population density of each rotational state [25]. The rotational states are populated according to a Boltzmann distribution with a rotational temperature used as a fit parameter. This theoretically obtained spectrum is convoluted with the instrumental profile obtained experimentally from the Rayleigh signal. The profile is fitted to the experimental data with a least squares method using rotational temperature and pressure (and thus air density) as fit parameters. The error in the Raman spectra is basically increasing with increasing temperature due to the drop in intensity and due to the outward shift of the intensity maxima outside the spectral range of the triple grating spectrograph $(5 \mathrm{~nm}$ from the laser wavelength [26]).

In the case of Rayleigh scattering, when the pressure of the plasma is known, the gas temperature can be obtained from the measured density by the ideal gas law. The scattered intensity $I_{\mathrm{sc}} \propto \sigma_{\mathrm{R}} \cdot n_{\text {gas }}$ with $n_{\text {gas }}$ the gas density and $\sigma_{\mathrm{R}}$ the cross section for Rayleigh scattering. Considering the ideal gas law at atmospheric pressure one obtains

$$
T \propto 295 \mathrm{~K} \cdot \frac{I_{\mathrm{sc}}(295 \mathrm{~K})}{I_{\mathrm{sc}}(T)},
$$

where $I_{\mathrm{sc}}(295 \mathrm{~K})$ is the Rayleigh signal when the plasma is switched off. The error on the Rayleigh scattering measurements is a statistical error (equal to the standard 
deviation of multiple measurements). Special care was taken to ensure that the Rayleigh measurement was not interfered with by stray light. Stray light made it only impossible to measure close to the electrodes (see further). It is evident that with the triple grating spectrometer, stray light is not an issue for Raman scattering [26].

The Rayleigh and Raman measurements are performed with the triple grating spectrograph reported in detail in [26], which has been developed for Thomson scattering measurements. For Rayleigh scattering measurements the mask of the triple grating spectrograph, which removes the laser wavelength for Raman and Thomson measurements, is removed. A frequency doubled Nd: YAG laser (Continuum, $532 \mathrm{~nm}$ ) is used that produces $100 \mathrm{~mJ}, 7 \mathrm{~ns}$ laser pulses with a pulse repetition rate of $10 \mathrm{~Hz}$. The laser beam has a waist of approximately $200 \mu \mathrm{m}$, which is of the same magnitude as the spatial resolution of the Rayleigh measurement in section 4 (as determined by the mechanical positioning of the plasma).

The gas temperature obtained by Rayleigh scattering is compared with the gas temperature obtained by Raman scattering for a radial cross section of the discharge at a current of $15 \mathrm{~mA}$ (figure 3). The cross section for Rayleigh scattering depends on the composition of the gas; a higher concentration of water vapour could reduce the total cross section up to $4 \%$ and $10 \%$ for $10 \%$ and $30 \%$ of water vapour in the discharge, respectively [27]. An upper limit of the water vapour concentration in a discharge between two liquid electrodes is estimated by Andre et al [19]. They obtained maximum water vapour percentages of $25 \%$ and $45 \%$ in the anode and cathode regions, respectively. The water vapour concentration in a metal pin-water electrode system is expected to be the lower limit of these values, which is consistent with the results previously obtained in $\mathrm{He}-\mathrm{N}_{2}-\mathrm{H}_{2} \mathrm{O}$ mixtures [9]. From figure 3 it is clear that good agreement is found when comparing the gas temperatures obtained by Rayleigh and Raman scattering, so that Rayleigh scattering can be considered as a reliable gas temperature measurement. However, the error on the gas temperature obtained by Raman scattering is very high in the centre of the discharge, which is mainly due to the low intensity of the signal at elevated temperatures and uncertainty on the baseline.

\section{Comparison of the gas temperature obtained by Rayleigh scattering and OES in the positive column}

The gas temperature in the positive column obtained by Rayleigh scattering and the rotational temperatures of $\mathrm{N}_{2}(C)$ and $\mathrm{OH}(A)$ are shown in figure 4 as a function of current. A clearly increasing trend with current is observed for the gas temperature obtained by Rayleigh scattering, whereas the rotational temperature obtained from $\mathrm{OH}(A)$ remains constant in all cases. Rotational temperatures of $\mathrm{OH}(A)$ obtained in the past by Bruggeman et al for an almost identical setup using rotational levels up to $J=15$ are also independent of the current and amount to $3300 \pm 250 \mathrm{~K}[7,8]$. An increase in the rotational temperature of $\mathrm{N}_{2}(C)$ with current is also found in this work which corresponds within the experimental accuracy to the gas temperature obtained by Rayleigh scattering. The

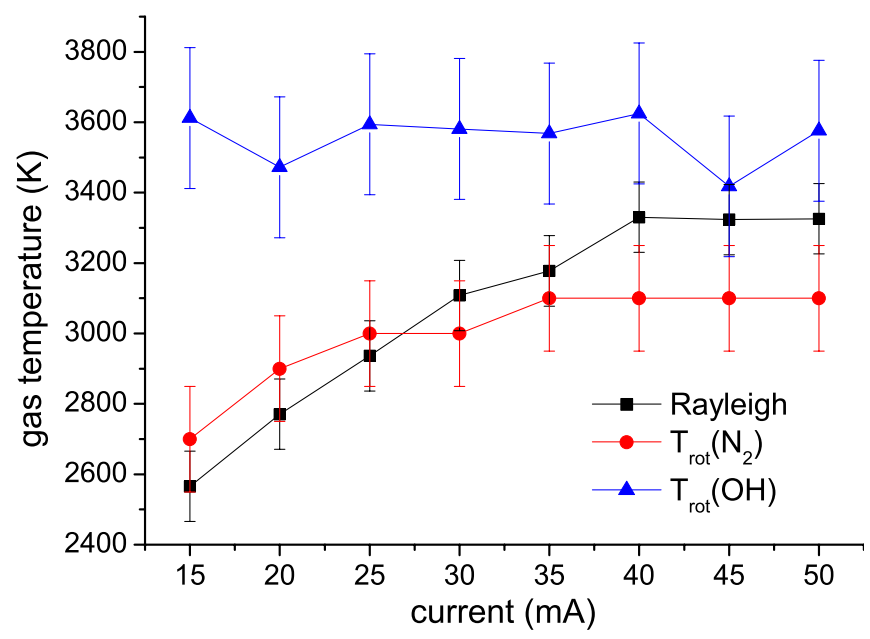

Figure 4. Gas temperatures in the positive column as a function of current measured by Rayleigh scattering and optical emission spectroscopy of $\mathrm{N}_{2}(C-B)$ and $\mathrm{OH}(A-X)$.

latter can be considered as an appropriate measurement of the gas temperature as discussed above (figure 3 ). This shows that the rotational temperature of $\mathrm{OH}(A)$ is indeed not a good representation of the gas temperature, even when the rotational population distribution seems to be Boltzmann (apart from the levels $J \leqslant 3$, figure 1 ). The curve of Rayleigh temperatures is steeper than the curve of rotational temperatures of $\mathrm{N}_{2}(C)$. In any case it is clear that the gas temperature will not be higher than the rotational temperature of $\mathrm{OH}(A)$. This means that the maximal underestimation of the gas temperature by Rayleigh scattering is $10 \%$, which corresponds to a water concentration of $30 \%$ in the discharge (for the highest current). This is indeed consistent with the results presented in section 2 . It is clear that when using OES to obtain the gas temperature a heavy molecule which is not produced in a dissociation process should be used.

An increase in the gas temperature with current follows from an increase in power and is also observed by Staack et al for an atmospheric glow discharge in air between two metal electrodes [28]. Even non-radially resolved OES of $\mathrm{N}_{2}(C-B)$ gives the highest temperature, which indicates that the emission originates from the core of the plasma. The extremely high rotational temperatures of $\mathrm{OH}(A)$, ranging from 4000 up to $5000 \mathrm{~K}$ measured by Marcus and Davis [5] and Mezei et al [6] under similar conditions, are an unrealistic representation of the gas temperature and $3300 \mathrm{~K}$ for the higher current situations seems a more realistic upper limit. For higher currents $(40-50 \mathrm{~mA})$ the rotational temperature of $\mathrm{OH}(A)$ seems to approach the gas temperature, which can be due to a better thermalization of the rotational population distribution of $\mathrm{OH}(A-X)$ [9]. Also, in high temperature discharges, such as arc discharges, the emission from $\mathrm{OH}(A-X)$ gives a realistic indication of the gas temperature $[12,29]$. However, the relative change in the spectrum of $\mathrm{OH}$ decreases with increasing temperature and, as a consequence, the accuracy of the gas temperature determination decreases.

The gas temperature measured in this work is higher than in the case of a glow discharge in air between two metal electrodes [30], where the gas temperature has a maximum 


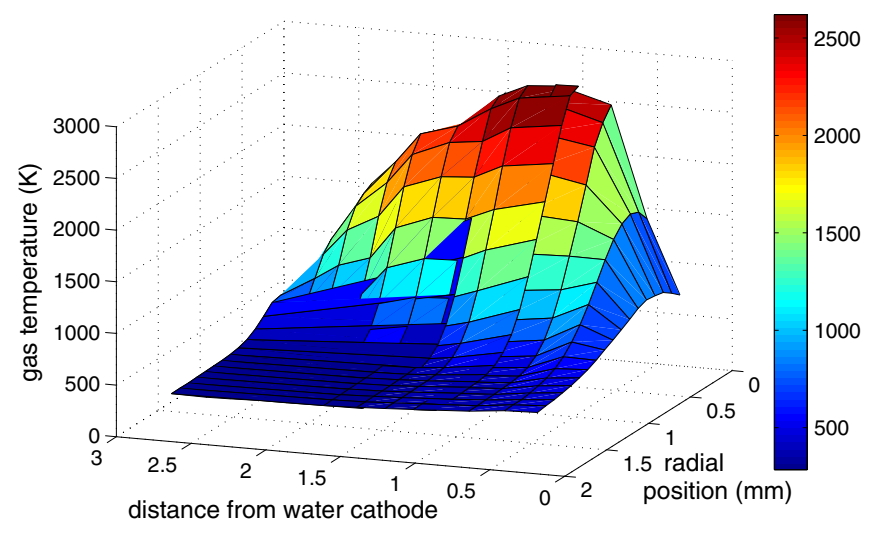

Figure 5. Two-dimensional profile of the gas temperature as a function of the distance from water cathode at $15 \mathrm{~mA}$ measured by Rayleigh scattering.

value of $2470 \mathrm{~K}$ at $92 \mathrm{~mA}$ (in the positive column). The hotter gas temperature (in the positive column) in the current case is due to a larger concentration of water vapour in the discharge. Since water has a higher $V-T$ rate than $\mathrm{O}_{2}$ and $\mathrm{N}_{2}$ and the $V-V$ process of $\mathrm{O}_{2}-\mathrm{H}_{2} \mathrm{O}$ and $\mathrm{N}_{2}-\mathrm{H}_{2} \mathrm{O}$ is fast, additional gas heating occurs compared with pure air as recently shown by Ono et al [31]. They found an increase in temperature by about a factor of two for an increase in water vapour concentration from $0.5 \%$ up to $2.4 \%$ in streamer discharges.

\section{Spatial distribution of the gas temperature}

A two-dimensional profile of the gas temperature as a function of the distance from the water cathode at $15 \mathrm{~mA}$ is shown in figure 5 . The temperature profiles are measured by Rayleigh scattering. The gas temperature has a maximum in the positive column $(2700 \pm 100 \mathrm{~K})$ and decreases towards the electrodes $(850 \pm 100 \mathrm{~K}$ and $700 \pm 100 \mathrm{~K}$ at the water cathode and the metal anode, respectively). Due to stray light coming from the water electrode, it was not possible to obtain a gas temperature from the region very close to the water cathode.

The gas temperatures obtained in the anode and cathode region are much lower than the gas temperatures measured by Mezei et al [6], who found unrealistically high temperatures of $8000 \mathrm{~K}$ and $6000 \mathrm{~K}$ from the emission of $\mathrm{OH}(A-X)$ in the near cathode and anode region respectively. Bruggeman et al [8] reported a drop in the rotational temperature of $\mathrm{N}_{2}(C)$ in the water electrode region. Nonetheless, the rotational temperature of $\mathrm{N}_{2}(C)$ at the electrodes $(2200 \pm 200 \mathrm{~K}$ and $1400 \pm 200 \mathrm{~K}$ in the near-cathode and anode region, respectively) are higher than the gas temperatures in this work [8]. The Rayleigh scattering measurement did not allow us to measure in the anode sheath, as the sheath only has a width $100 \mu \mathrm{m}$. The gas temperature in the anode region could be somewhat higher, as measured by Staack et al [32], but because of the relatively low spatial resolution this could not be measured.

The rotational temperature of $\mathrm{N}_{2}(C-B)$ in the cathode layer, measured by Bruggeman et al [7], is much larger than the gas temperature obtained from Rayleigh scattering. This can be explained because the discharge is filamentary in nature when close to the cathode [8]. The temperature obtained from Rayleigh scattering is not the local temperature in the filament but an averaged temperature of the gas, while the emission of $\mathrm{N}_{2}(C)$ for the rotational temperature measurement arises from localized filaments in the plasma where the gas temperature is higher.

In the next paragraph, the gas temperature gradients towards the electrodes are checked to be consistent with the power dissipation in the plasma with some straightforward estimates. Starting from the equation for the power input per unit length

$$
\frac{P}{l}=i E,
$$

where $i$ is the discharge current and $E$ the electric field, the power in the positive column $P_{\mathrm{PC}}$ can be calculated. At a current of $15 \mathrm{~mA}$ and an electric field in the positive column of $95 \mathrm{~V} \mathrm{~mm}^{-1}$ [9], $P_{\mathrm{PC}}$ equals $4.3 \mathrm{~W}$ while the total power is $16.4 \mathrm{~W}$. According to the measurements of Stepaniuk et al in a similar discharge in air [30], 50\% of the power in the positive column goes to convection losses, so in this case about $2.2 \mathrm{~W}$ goes to convection losses. From Fourier's law of conduction we estimate the radial losses by thermal conduction to be $1.7 \mathrm{~W}$. This means that the temperature gradient at the anode and cathode needs to be

$$
\left(\left|\frac{\partial T}{\partial x}\right|_{\mathrm{a}}+\left|\frac{\partial T}{\partial x}\right|_{\mathrm{c}}\right) \approx \frac{0.5 \mathrm{~W}}{k \pi r^{2}},
$$

where $k$ is the thermal conductivity of the gas and $r$ is the radius of the discharge $(r \approx 0.5 \mathrm{~cm})$. As the cathode gradient is about twice the anode gradient, $\Delta T \approx 2300 \mathrm{~K}$ is obtained for $\Delta x=0.5 \mathrm{~mm}$, corresponding to the observed distance for which the gas temperature is starting to drop significantly. A temperature gradient of $\approx 2300 \mathrm{~K}$ is about the same order as the temperature drop observed in figure 5 .

\section{The effect of polarity of the liquid electrode}

Rayleigh scattering measurements have additionally been attempted for positive polarity of the liquid, but it was not possible to obtain reliable data due to the irregular movement of the discharge when the water electrode is the anode. Nonetheless to compare the water cathode and anode cases, and thus to discuss the influence of the polarity, we present the spatially-averaged but time-resolved gas temperature obtained from the rotational temperature of $\mathrm{N}_{2}(C-B)$ for a $600 \mathrm{~ns}$ pulsed discharge for both polarities (figure 6). For details the reader is referred to [33]. In the case of the water cathode, filamentation leads to strong heating while the diffuse discharge in the case of the water anode remains rather cold $(<1000 \mathrm{~K})$. As shown by Bruggeman et al [8] the gas temperature close to the water anode in the dc equivalent drops to $750 \mathrm{~K}$ (even with limited spatial resolution), while the gas temperature in the water cathode region is $2200 \mathrm{~K}$. This clearly indicates that in the water anode case the gas temperature near the water surface will also decrease towards room temperature. Since the electric field and current in the positive column are polarity independent, this is consistent with the estimations of the temperature gradient made in the previous section. 


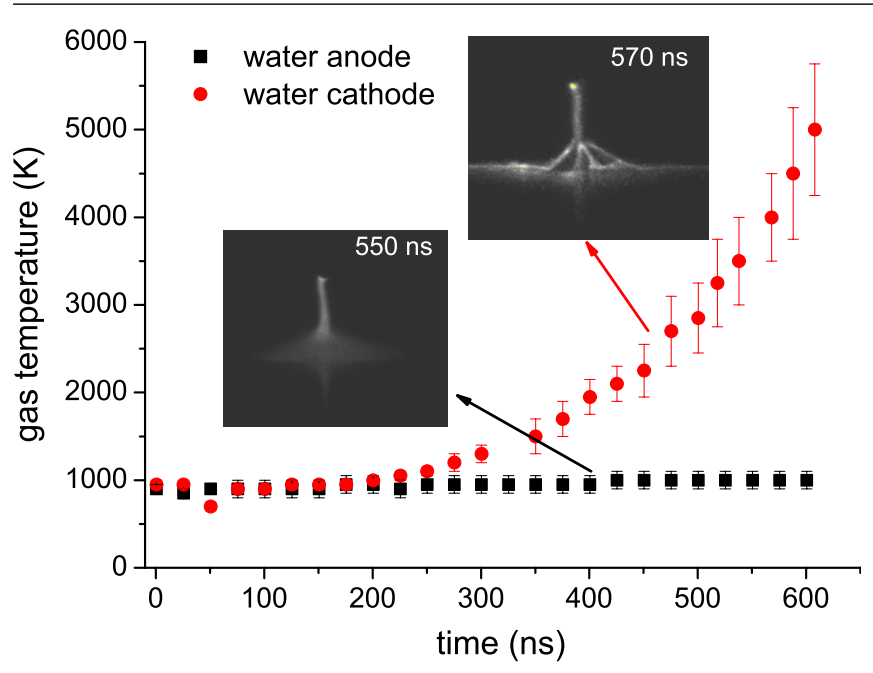

Figure 6. Evolution of the gas temperature during a $600 \mathrm{~ns}$ pulsed discharge for both polarities. The applied voltage is $4 \mathrm{kV}$, the current is $1-4 \mathrm{~A}$ and $0.3-0.5 \mathrm{~A}$ for the water cathode and anode, respectively. The inter-electrode distance is $1.5 \mathrm{~mm}$. See also [33].

\section{Conclusion}

The gas temperature of an atmospheric pressure glow discharge with a water cathode was measured by Rayleigh scattering and was compared with gas temperatures obtained from optical emission spectroscopy of $\mathrm{OH}(A-X)$ and $\mathrm{N}_{2}(C-B)$. The gas temperature obtained from Rayleigh scattering and the rotational temperature of $\mathrm{N}_{2}(C)$ show a clear increase in the current range $15-40 \mathrm{~mA}$, while the rotational temperature of $\mathrm{OH}(A)$ remains constant. At $15 \mathrm{~mA}$ the rotational temperature in the positive column calculated from the emission of $\mathrm{OH}(A)$ is $3600 \pm 200 \mathrm{~K}$, while the gas temperature obtained from Rayleigh scattering and the rotational temperature of $\mathrm{N}_{2}$ are, respectively, $2600 \pm 100 \mathrm{~K}$ and $2700 \pm 150 \mathrm{~K}$.

In spite of the same quenching cross section of $\mathrm{N}_{2}(C)$ as for $\mathrm{OH}(A)$ in collision with $\mathrm{H}_{2} \mathrm{O}$, the rotational temperature of $\mathrm{N}_{2}(C)$ is a good estimate of the gas temperature. The RET of $\mathrm{N}_{2}(C)$ is faster than in the case of $\mathrm{OH}(A)$ due to its higher mass. This means that it is better to use heavier molecules such as $\mathrm{N}_{2}$ for which thermalization of the rotational states is not inhibited by quenching.

There is a strong temperature gradient near the electrodes, consistent with the power dissipation and heat transfer. The temperature in the filaments near the water cathode $(\approx 2200 \mathrm{~K})$ is much higher than the averaged gas temperature in this region $(\approx 800 \mathrm{~K})$.

\section{Acknowledgments}

TV and PB obtained part of the results presented in figure 6 during their stay at Loughborough University and would like to thank professor Michael Kong and Dr James Walsh. The authors acknowledge professor Leys (Ghent University) for lending us the glow discharge setup after TV joined Eindhoven University of Technology.

\section{References}

[1] Bruggeman P and Leys C 2009 J. Phys. D: Appl. Phys. 42053001

[2] Stalder K R, Mcmillen D F and Woloszko J 2005 J. Phys. D: Appl. Phys. 38 1728-38

[3] Sunka P 2001 Phys. Plasmas 8 2587-94

[4] Mitra B, Levey B and Gianchandani Y B 2008 IEEE Trans. Plasma Sci. 36 1913-24

[5] Marcus R K and Davis W C 2001 Anal. Chem. 73 2903-10

[6] Mezei P, Cserfalvi T and Csillag L 2005 J. Phys. D: Appl. Phys. 38 2804-11

[7] Bruggeman P, Ribezl E, Maslani A, Degroote J, Malesevic A, Rego R, Vierendeels J and Leys C 2008 Plasma Sources Sci. Technol. 17025012

[8] Bruggeman P, Liu J, Degroote J, Kong M G, Vierendeels J and Leys C 2008 J. Phys. D: Appl. Phys. 41215201

[9] Verreycken T, Schram D C, Leys C and Bruggeman P 2010 Plasma Sources Sci. Technol. 19045004

[10] Pellerin S, Cornier J M, Richard F, Musiol K and Chapelle J 1996 J. Phys. D: Appl. Phys. 29 726-39

[11] Laux C O, Spence T G, Kruger C H and Zare R N 2003 Plasma Sources Sci. Technol. 12 125-38

[12] de Izarra C 2000 J. Phys. D: Appl. Phys. 33 1697-704

[13] Bruggeman P, Schram D C, Kong M G and Leys C 2009 Plasma Process. Polym. $6751-62$

[14] Bruggeman P, Iza F, Guns P, Lauwers D, Kong M G, Gonzalvo Y A, Leys C and Schram D C 2010 Plasma Sources Sci. Technol. 19015016

[15] Bruggeman P, Verreycken T, Gonzalez M A, Walsh J L, Kong M G, Leys C and Schram D C 2010 J. Phys. D: Appl. Phys. 43124005

[16] Kienle R, Lee M P and Kohse-Höinghaus K 1996 Appl. Phys. B 62 583-99

[17] Kliner D A V and Farrow R L 1999 J. Chem. Phys. $110412-22$

[18] Barinov Yu A and Shkol'nik S M 2002 Tech. Phys. 47 313-9

[19] Andre P, Aubreton J, Yu. Barinov, Elchinger M F, Fauchais P, Faure G, Kaplan V, Lefort A, Rat V and Shkol'nik S 2002 J. Phys. D: Appl. Phys. 35 1846-54

[20] Meinel H and Krauss L 1968 J. Quant. Spectrosc. Radiat. Transfer 9 443-60

[21] Mohlmann G R, Beenakker C I M and De Heer F J 1976 Chem. Phys. 13 375-85

[22] Pancheshnyi S V, Starikovskaia S M and Starikovskii A Yu 2000 Chem. Phys. 262 349-57

[23] Verreycken T, Bruggeman P and Leys C 2009 J. Appl. Phys. 105083312

[24] Laux C O 2002 www.specair-radiation.net

[25] Penney C M, Peters R L St and Lapp M 1974 J. Opt. Soc. Am. $64712-6$

[26] van de Sande M J, Deckers R H M, Lepkojus F, Buscher W and van der Mullen J J A M 2002 Plasma Sources Sci. Technol. 11 466-75

[27] Sutton J A and Driscoll J F 2004 Opt. Lett. 29 2620-2

[28] Staack D, Farouk B, Gutsol A F and Fridman A A 2006 Plasma Sources Sci. Technol. 15 818-27

[29] Maslani A and Sember V 2009 High Temp. Mater. P-US 13 205-15

[30] Stepaniuk V P, Ioppolo T, Ötügen M V and Sheverev V A 2007 J. Appl. Phys. 102123302

[31] Ono R, Teramoto Y and Oda T 2010 Plasma Sources Sci. Technol. 19015009

[32] Staack D, Farouk B, Gutsol A F and Fridman A 2007 IEEE Trans. Plasma Sci. 35 1448-55

[33] Bruggeman P, Walsh J L, Schram D C, Leys C and Kong M G 2009 Plasma Sources Sci. Technol. 18045023 